Orville is stepping aside to continue research and teaching as a distiguished professor in the department and as head of the Numerical Modeling Group in the Institute of Atmospheric Sciences. Orville is a Fellow of the AMS and is the chairperson of the Scientific and Technological Activities Committee. He is also a member of AMS's Public Policy Committee.
Helsdon is a professor in the department, which he joined in 1979 after receiving his Ph.D. at the State University of New York-Albany. He pursues research in atmospheric electricity and teaches courses in that topic as well as precipitation physics and physical meteorology. Paul L. Smith continues as director of the Institute of Atmospheric Sciences.

Editor's note: The August 1969 Bulletin, in the "News from Our Chapters" section, contained the following report from the Greater Boston chapter, written by Patrick J. Harney.

\title{
Greater Boston
}

The May dinner meeting was held at Piety Corner Gardens in Waltham. Prof. Hurd C. Willett of MIT delivered the evening talk, entitled "A long range view of weather forecasting."

Speaking from his own experience, Prof. Willett added statistics and opinions in the right proportion to make the accounting historical. After graduation from Princeton in 1924, the speaker found himself working in the Weather Bureau with Marvin, Mitchell, and Humphreys along with students Dunn and Van Thullenar and a navy representative, Reichelderfer. Forecasting of surface weather was learned through experience, close application of the student to the few charts available, and a constant review of Weather Bureau scores, entered by Robinson in a "doomsday book." During the same year Rossby, who later established the department at MIT where Willett joined him in 1929, arrived at the Weather Bureau. This marked a decade of development of polar front theory and airmass analysis, with MIT beginning aerological observations in 1930; although, disappointingly enough, forecast skills did not improve during this transitional period.

Raobs and rawins became available during the next decade which he named the Upper Air Period. With the impact of World War II, the expansion in numbers of forecasters and in the variety of forecasts went far beyond any earlier projections. If records had been kept, however, the day-to-day forecasts of the surface weather would still probably have shown no improvement. The forecaster was being submerged in more and more data without the chance to analyze it. About this time Namias, first at MIT with Willett and then in 1941 at the Weather Bureau, started 5-day forecasting. Fortunately a record of accuracy of this effort was kept and showed that by the fifth day the forecast probability was little better than chance.

Starting about 1949 with von Neumann and Charney at Princeton, computers were put to work, and by 1958 the age of the computer in weather forecasting had begun. The advantages were enormous, not the least being the freeing of the forecaster for better analysis, but disadvantages were also apparent. The model chosen for analysis is a simplification and the machine cannot learn from its mistakes. It is difficult for the user to rationalize the behavior since he has not gone through the processes which provided feedback in the old system. Perhaps the primary difficulty is that an upper air prognosis is available which must be translated into a surface map from which the forecaster works as before. A greater number of variables can go into this effort, but basically it is an iterative process which has limitations. Lorenz at MIT has recently worked out some statistics on the effect of the accumulation of errors and has shown that averages from the computer use are not much better than the curve shown before, and there is no likelihood of skill beyond the proposed 14-day period. The World Weather Watch program will remove some of the boundaries, but still offers no new solution to improve day-to-day forecasting.

Bull. Amer. Meteor. Soc., 50, 634-635. 